Article

\title{
Shortcomings and Suggestions to the EPC Recommendation List of Measures: In-Depth Interviews in Six Countries
}

\author{
Alex Gonzalez Caceres ${ }^{1,2}$ (D) \\ 1 Department of Civil Engineering, Technical University of Denmark, 2800 Kongens Lyngby, Danmark; \\ aagc@byg.dtu.dk or alexgc@oslomet.no; Tel.: +47-477-225-63 \\ 2 Department of Civil Engineering and Energy Technology, OsloMet-Oslo Metropolitan University, \\ 0130 Oslo, Norway
}

Received: 29 August 2018; Accepted: 17 September 2018; Published: 21 September 2018

\begin{abstract}
Dwellings built between 1945 and 1980 have the largest energy demand in the EU, which by 2009 represented $70 \%$ of the final energy use in buildings. A great portion of these dwellings have not been retrofitted and most of them were not built with any energy efficiency measures, since most of the energy regulations were implemented after the oil crisis in the 70s. To face this issue several actions were taken in the EU, among these, the implementation of Energy Performance Certification, which includes a Recommendation List of Measures (RLMs) to retrofit the property. The main objective of this study is to identify the weaknesses of the RLMs and to suggest changes to improve the quality and impact of this feature. The results indicate that to retrofit an existing building, the RLMs lack information for decision-making. The study suggests important barriers to overcome for achieving potential energy reductions in existing residential buildings, highlighting improvements to the recommendation content and its implementation.
\end{abstract}

Keywords: recommendation list of measures; energy performance certificate; residential buildings

\section{Introduction}

Building renovation presents an enormous potential for reduction of energy, which is more ambitious than the potential that the energy savings from new buildings would give [1,2]. However, efforts are more focused on new buildings reaching net zero-energy than on renovation of existing buildings [3]. Despite this, retrofitting of building stock is still a priority in Europe [4]. It is well known that a great portion of the current building stock was built before serious energy efficient standards were in place [5]. This might explain why residential buildings consume almost $25 \%$ of the total energy use in the building sector in the EU [6]. With this, energy savings can be achieved in existing dwellings more cost effectively than any other sector [7]. Consequently, this led to the amending proposal of the Directive 2010/31/EU to member states (MSs), stating that its objective is to accelerate the cost-effective renovation of existing buildings, which represents a 'win-win' option for the EU economy as a whole [8].

As reported by the European Commission [9], a dramatic increment on the energy consumption is projected from 2012 to 2040, and due to this, several actions have been taken in the EU to reduce global warming and convert Europe into a competitive low carbon economy by 2050. The Commission has drawn attention to the existing building stock since energy performance of the built environment would drastically improve through refurbishment of old buildings, among others. This would enable MSs to achieve their commitment to achieve 20\% improvement in energy efficiency by 2020 .

One of the most concrete actions at the EU level to reduce the energy consumption according to the Commission $[10,11]$ is the creation of the Energy Performance of Buildings Directive (2010/31/EU) 
and the Energy Efficiency Directive (2012/27/EU). These directives have developed legislations aiming to provide the EU with up to 65 Mtoe savings in the buildings sector by 2020. With these legislations, MSs commit to create an overview of their national building stock, to identify cost-effective ways to renovate according to building type and climate, and to create policies including a list of national measures for funding energy efficiency renovations. Furthermore, it is required that existing buildings undergoing major renovation meet minimum energy performance requirements in so far as this is technically, functionally and economically feasible [12]. One of the tools that is closely related to the previous goals is the Energy Performance Certificate (EPC), which states that for the existing building the EPC must include recommendations for the cost-optimal or cost-effective improvement of the energy performance of a building or building unit. Moreover, it is mentioned that EPCs intend to provide accurate and valuable information to building owners and tenants on the energy performance of their buildings. Measures to ensure quality information are the requirement for qualification schemes for experts, quality control and enforcement, which must be ensured, in particular through national independent control systems that MSs must set up in line with the Energy Performance of the Building Directive (EPBD) requirements.

Increasing the renovation rate is not an easy task. There are many obstacles that prevent retrofitting from taking place, and these need to be addressed to find effective solutions. Studies which focused on the barriers that explain the low retrofitting activity of residential buildings are numerous, and identify a wide range of barriers as influential factors [13], such as legal and organizational barriers [14,15], economic barriers [2,16,17], lack of benefits [18], technical barriers [19,20], etc. However, it has been identified that along with the financial barriers the lack of information is one of the main obstacles associated with energy performance improvement in the residential sector [2,21-23]. With this, the EPC can be seen as a reaction to the "information deficit" [21], referring to building owners' lack of knowledge of actions to take in order to enhance the energy performance of their building [24]. Despite the EPC's potential to provide information, the RLMs have not been studied in-depth. Moreover, recent reports have shown that the influence of the RLMs is limited $[11,25,26]$. This is perhaps due to the short period since its implementation [27] given that new technologies-even if they present great advantages-require a gradual introduction [28]. However, there is a need for deeper information about the performance of this tool and how to improve it along with other complementary policies. This is confirmed in the latest update of the EPBD, since the current directive 2018/844/EU [29] does not propose any changes to the articles related to the EPC or the RLMs and, as is explained further down, the material presented in the evaluation used to amend the EPBD hardly touches upon the RLMs and its effectiveness.

The relevance of the work and its contribution to the research field lies in the analysis of an underlooked feature in the EPC, identified by the author as one of the main policy tools to overcome the renovation deficit in the EU. Despite that some information can be found, the data is scarce and normally mixed within EPC studies. The lack of discussion on the RLMs has stalled its development, preventing improvements from being proposed. In this context, this study aims to provide valuable information about the RLMs contributing to filling the existing gap on this tool. To accomplish this, results are presented by categories; each including a literature review on the topic, followed by the results of interviews conducted with certifiers. The second aim is to analyze and process the presented information to identify weak points and suggest improvements geared to take advantage of the opportunities that RLMs could bring.

\section{Theoretical Background}

\subsection{Energy Performance Certificates}

To present a full picture of the RLMs, first it is necessary to address the EPC and the certification procedure, given that the RLMs is part of this system. The EPC was introduced at European level in the EPBD 2002. Its main goal is to reduce $\mathrm{CO}_{2}$ emissions by increasing the investment in energy 
efficiency by serving as an information tool and market transformation mechanism [30]. The certificate is required whenever a building is constructed, or for existing buildings before being marketed for sale or rent. EPCs are produced using standard methods with standard assumptions about energy usage so that the energy efficiency of one building can easily be compared with another building of the same type [31]. This allows prospective buyers, tenants, owners, and occupiers to see and compare information on the energy efficiency and carbon emissions from a building, so they can consider energy efficiency and fuel costs as part of their investment decision.

\subsection{Recommendation List of Measures}

With the EPBD recast (2010/31/EU) the certification scheme for existing buildings was strengthened by including a mandatory recommendation report, listing measures to improve the energy performance of the building, known as RLMs. The directive requested that these recommendations shall be cost-optimal or cost-effective and technically feasible. Moreover, the evaluation of cost-effectiveness of the measures shall be based on a set of standard conditions, such as the assessment of energy savings and underlying energy prices and a preliminary cost forecast. The RLMs should be in connection with a major renovation of the building envelope or technical building system and contain information on the steps to be taken to implement the recommendations and it may provide an estimate for the range of payback periods or cost-benefits over its economic lifecycle. Other information on related topics, such as energy audits, incentives or other nature of financing possibilities may also be provided to the owner or tenant [32]. The scheme of the EPC and RLMs' requirements can be seen in Figure 1.

EPCs along with the RLMs and inspection reports intend to provide information to building owners and tenants on the energy performance of their buildings, heating and air-conditioning systems, and on effective ways to improve these through building renovation works [11].

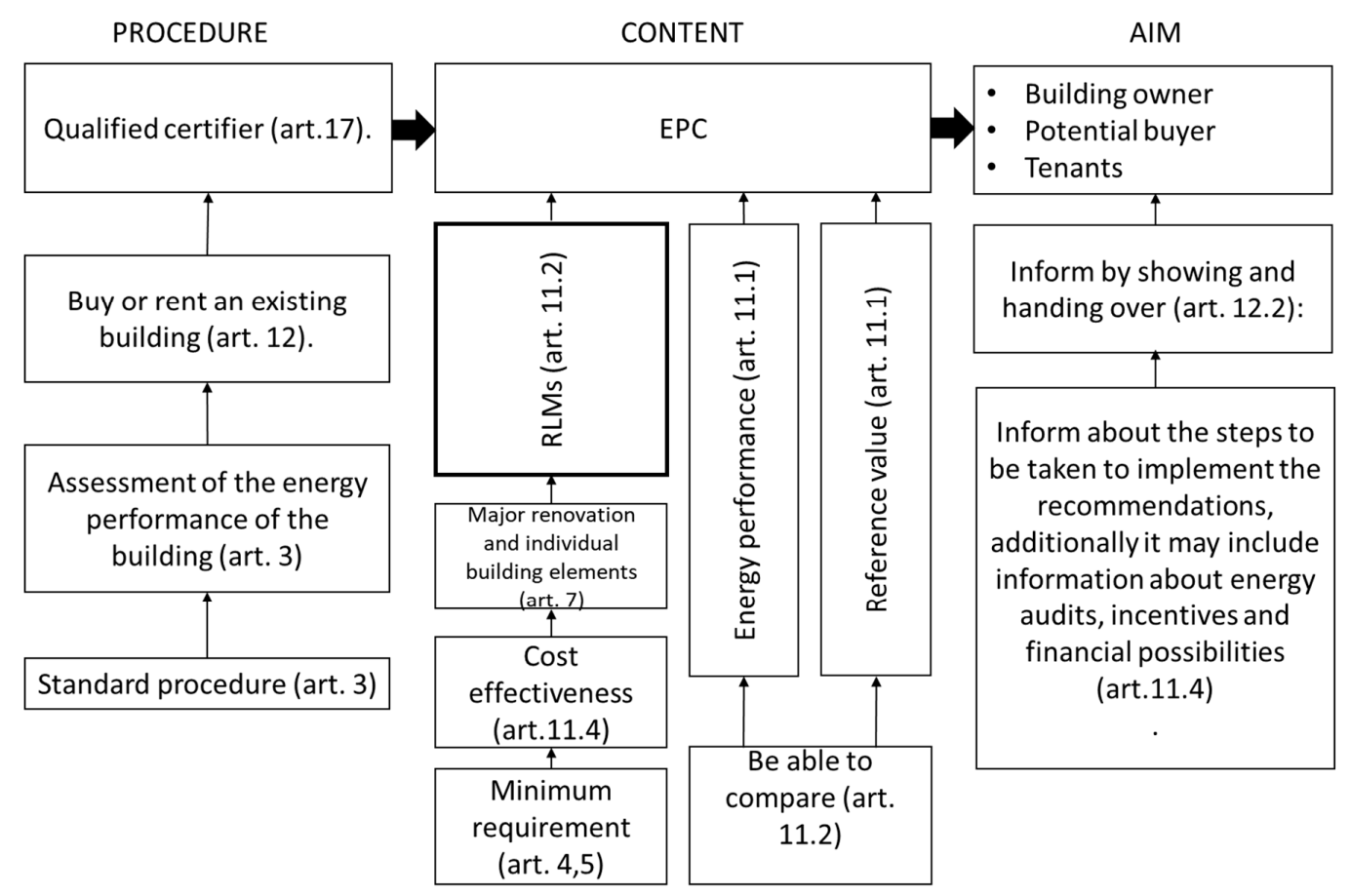

Figure 1. General scheme of the EPC and RLMs requirements.

\subsection{Current Research Status of RLMs}

As mentioned previously, the RLMs has not been studied in-depth and most of the information related is found in studies related to the EPC. Under the extensive literature review during this research, 
two reports stand out as a source of information on the status of RLMs, the evaluation of the Directive 2010/31/EU [11] and the CA-EPBD report [27].

The evaluation of the Directive 2010/31/EU provides the basis for the Impact Assessment of policy options performed in the framework of the EPBD. The evaluation covers the entire EPBD and is organized around five concepts: effectiveness, efficiency, relevance, added value, and coherence. The material used in the evaluation is based on several sources, such as reports, research papers, consultations, and technical workshop to the main stakeholders.

The evaluation emphasizes the relevancy of the existing building stock, in particular, it states that increasing the rate, quality and effectiveness of building renovations is the biggest challenge for the next decades. This reinforces the importance of RLMs as an instrument to achieve these goals. Nevertheless, the document does not refer to the RLMs directly; only at the annex 10 (Evaluation of the efficiency) several statements can be found that can be associated with the RLMs' performances. In summary, it indicates that the performance of RLMs is affected by the lack of information, requirements, and trust. Lack of information on how to plan and implement improvements in energy efficiency in buildings over time; lack of requirements for reporting potential measures or the absences of appropriate RLMs of measures; and limited trust in EPC in some MSs, which again limits the potential role that recommendations can play.

On this matter, the report concluded that policies related to energy performance ratings and recommendations should explore new approaches to remove the barriers to lead a transformation of the building stock. In their current state, only providing tailor-made energy performance recommendations, they have proven to be insufficient to trigger investments.

The main study that focuses specifically on the RLMs is the report from CA-EPBD [27], where several topics targeting the RLMs are presented. It states that RLMs are an important support tool for building owners, facilitating the decision-making about renovation measures. It also identifies issues regarding how the requirements for the recommendations list were designed. There is a lack of clear definitions of tailor-made and standard, as well as of what type of information should be included. EPCs in some cases only displayed general information about renovation measures; financial incentives and payback periods are often missing. This flexibility generates a wide range of RLM types with diverse qualities and therefore diverging EPC prices.

The report concluded that there is a lack of statistical data on the number and type of RLMs implemented, suggesting that this information should be collected in a database to analyze the trend of the measures applied. With this, financing methods can be proposed as well, to improve the building stocks. Furthermore, it also mentions the difficulties that arise from lacking a clear definition of what cost-effectiveness of refurbishment measures actually means. This leads to a wide range of methodological differences among MSs. The report suggests that more research is needed to explore different aspects that influence the investment decisions on energy efficiency, facilitating the transition of the building stock to Nearly Zero-Energy Buildings.

\section{Method}

To analyze the role of the RLMs as a tool to support a home renovation project, a qualitative research method was used. Two main tasks were performed to address these issues, a literature review and in-depth interviews to certifiers.

A literature review was performed seeking to learn and clarify how the RLMs are produced and implemented at different levels. This task involved three sources of information, official reports, and documents from the European commission, reports from research institutions and research projects funded by the EU, and scientific research articles. The information gathered was structured to inform comprehensively about how the RLMs are designed, performed, and used by different stakeholders. Through the literature review, the main gaps and concerns were identified, which were used to prepare the questionnaire for the interviews. To organize the information, five topics were designed to analyze the RLMs. 
Development of the RLMs: The proposed topic focuses on how the RLMs are designed, including the calculation behind and its procedure. It also covers the drawback concerning standard RLMs, since it is the most common procedure followed by MSs [33]. Among other questions developed for this category were: Describe the procedure required to obtain an EPC and the RLMs-What is mandatory and what can be flexible?-What process of the EPC you find that can be improved to help the energy consultant?

Usefulness and quality of the RLMs: Seeks to provide information about the relevance of the RLMs in a retrofitting process by using standard inputs and their implications on the results. As well, the content provided in the EPC regarding the RLMs that are not mandatory but recommended by the EPBD, such as the costs and payback time is revised. Among other questions developed for this category were: How long does it take to perform a field visit?-Is the list of recommendation measures accurate in terms of detecting the most important aspect of the retrofitting needs?

Information Impact of the RLMs: The content in the certificate and the RLMs is exposed under this section, where their impact on the users and what users think is relevant as information is also discussed. Among other questions developed for this category were: What type of questions do you often receive from the homeowners related to the EPC and the recommendation list?-What information do you find useful of the EPC to explain the state of the dwelling to the homeowners?

Investment on the RLMs: Despite that the content of the EPC and the calculation procedure has been delivered by the EPBD, there is still much freedom to move forward and make improvements. It is up to MSs to define how much they are willing to invest in the certification scheme and the RLMs. This section provides information on how much progress was made in the implementation of the RLMs from the minimum requirements from the EPBD. Among other questions developed for this category were: Do you think that improvements can be made in the certificate to have a similar quality evaluation as an audit?-Do you think that the EPC results can replace an audit?-Is the list of recommended energy saving measures accurate and trustworthy for the decision-making?

Management and data collection: The information from the EPC and RLMs can be collected and used in several ways. This section points out how this process is considered in the EPC scheme. Among other questions developed for this category were: Is there any link between the RLMs and incentives or funding opportunities? Is it mandatory to give homeowners more information about the recommendations list? Do you recommend them to ask for an energy audit?-How is the data from the EPC stored?

The interviews were carried out between June 2017 and February 2018 covering six countries: Denmark, Germany, Norway, Poland, Spain, and Sweden. In total, ten semi-structured in-depth interviews were undertaken with certifiers in companies of varying sizes, as can be seen Table 1 . The participants received the open-ended questionnaire and a short description of the research aims in advance to prepare for the interview. The sessions were performed mostly by an Audio/Video Communication Tool (Skype). The interviews were recorded and lasted between one and two hours depending on the motivation and knowledge of the certifier. The results were sorted in corresponding topics confirming and/or adding information to the subject.

Table 1. Information of companies and certifiers.

\begin{tabular}{ccc}
\hline Country & Company Size & Profession \\
\hline Norway & International & Engineer \\
Norway & International & Engineer \\
Denmark & International & Engineer \\
Denmark & Independent & Engineer \\
Sweden & International & Engineer \\
Poland & Local & Engineer \\
Germany & National & Engineer \\
Germany & National & Engineer \\
Spain & Independent & Architect \\
Spain & Independent & Architect \\
\hline
\end{tabular}




\section{Results}

\subsection{Development of the RLMs}

The RLMs can be manufactured by a standard method or be tailor-made by the certifier. In most cases it would be standard, since a customized approach would significantly increase the cost of the EPC [33]. The standard method requires to follow cost-optimal calculations according to the Guidelines of the EPBD Recast, Delegated Regulation (EU) No. 244/2012. To prepare the measures, a database about the existing building stock is required for selecting reference buildings, to subsequently identify the proper measures for renovations (ten measures at least), which additionally must guarantee to be cost-effective. The Directive requires at least two reference buildings for each typology (residential, commercial, public, etc.), which seems to be insufficient to represent a national building stock, considering there are other important characteristics such as construction type, climate, and year of construction [34]. Some studies have featured the importance of the Reference Building to propose significant renovation measures and the challenge that its choice represents [35,36]. Another remark about the calculations is the use of standard conditions which mean that the outcome cannot be directly compared with the actual performance, given that usually these results are not related [37]. By using those results, energy efficiency measures are tailored to comply with the Building Regulations' requirements, without necessarily considering procurement and operational risks [38]. The trust in the recommendations is a key element in encouraging the building owners to follow the advice [39]. Nevertheless, studies have shown that the users disagree or do not trust the suggestion on the RLMs [26,40,41].

All the participants in this study use a method that is closer to the standard approach for elaboration of the RLMs. These procedures fall in that category since all the interviewees explained that the recommendations are automatically originated by the labelling tool, or after the results are uploaded to the system. However, the final list can be improved or complemented, this will depend on the attributions that each country assigns to the certifier. In some cases, the RLMs can be modified by adding more measures, introducing costs, or delivering more specific information about the measures while in others changes are not allowed. The overall impression of the interviewees about the standard RLMs is that it effectively detects adequate solutions to improve the building, even though these are quite common, such as adding more insulation to the envelopes, replacing the windows, upgrade the boiler etc. However, some of them claim that to add more relevant and accurate measures, which may be more effective, it is strictly necessary to perform an inspection. This is because certain measures can only be detected by on-site visits such as reducing air leakages, changing the settings of the HVAC system or the existence of pipe insulation, which are highly cost-effective measures. Nevertheless, this is not a common practice, since this increases the cost of EPC and therefore is up to the building owner to decide how good the EPC should be. To this, all the interviewees agree that in most cases, the building owner is looking for the cheapest and fastest options. The quality of the recommendations varies in every country, some of them do not include the expected savings by implementing the recommendations, others include them, but not the renovations costs.

\subsection{Usefulness and Quality of the RLMs}

The Directive recommends that the EPC include the potential energy savings of the suggested measures, which has been implemented by some states. Despite this initiative, it is necessary to analyze the relevance of its incorporation. Given that the EPC is a labelling system whose objective is to allow comparing buildings in the same category, standardized procedure and inputs must be followed, which leads to the uses of simplifications and assumptions. Therefore, these estimates cannot be directly compared with the actual performance [37]. Accordingly, some studies indicate that, due to certain flaws in the calculation, such as the performance gap, the results may not be accurate enough, distorting the savings and the costs involved [42-44]. Recommendations that do not consider data from real energy consumption may give unrealistic benefits [25]. Furthermore, the costs lack 
information and do not suggest the total investment of the implementation of the measures [45]. In the case of RLMs without execution costs, studies suggest that real decisions cannot be taken just in light of the potential energy savings since the initial investment is one the most important factors that homeowners take into account before a renovation decision [43,46,47].

Most of the interviewees explained that because of the standard inputs, the results of the evaluation most likely would not match measured energy uses. However, the majority claim that the results are good enough to describe the quality of the building, and since the purpose of the EPC is to compare different options, they agree that this aspect is being solved correctly. However, if the building has been improved previously, e.g., adding insulation or replacement of the windows, this modification will not be counted in the calculation system, since the software uses standardized data based on the construction year to fill most of the information of the envelope. To avoid this the certifier should visit the building and detect the improvements, but often they leave it as it is since the information about the most common renovation measures, such as new windows or the properties of the added insulation, is normally unknown by the clients.

Two participants acknowledge that the potential energy savings presented by the tools were not good enough to just implement the measures, since they are dependent on the climate, and this issue has not been correctly handled in many cities of their respective countries. The rest of the interviewees agreed that RLMs are a good start, since they provide information to the building owners about what could be improved as an inspiration. Nevertheless, this information is not accurate enough to guarantee that the modification will be cost-effective. All the interviewees state that no iteration procedure is done with the software. Due to this, it is unknown which measure would be more effective, since this is not part of the requirements. To guarantee tailored cost-effectiveness measures, further advice is required to find the most proper choice.

\subsection{Information Impact of the RLMs}

The capacity to compare different properties, as in a labelling system, could raise the interest in energy efficiency, and with this, users may prioritize buildings that present lower energy demands, increasing the influence of energy efficiency on the market. With this regard, the incorporation of the RLMs in the labelling system was expected to help influence the market as well, since they provide information about investment opportunities [48]. Although this may be true, to evaluate its real impact may require more time. In the meantime, reports show that there is no substantial evidence to affirm that energy performance could influence the market price [42]. Another key point of the EPC is to provide useful information to the users. When in fact, it has been suggested that users do not use the EPC as a decision-making tool due to many reasons, such as lack of trust and understanding [25], it not seeming useful for home energy renovation purposes [45], or a preference for other sources [26]. Moreover, other reports have demonstrated that other factors are more relevant for the user interests, such as indoor air quality, health, comfort, etc. [49,50].

The interviewees agreed that the EPC may not have an impact on the value of the properties in the market, since they play a small role when it comes to desired building attributes (for renting or buying). Furthermore, their impression is that most clients request an EPC just as part of the bureaucratic requirements for making a transaction, and the results of the assessment are somehow irrelevant for the client (homeowner). Experiences related to a client asking for any advice in terms of energy efficiency, or how to improve the results of the label, are rare-this answer was similar in all the interviewees. Altogether, this suggests that the EPC has not impacted the users in terms of energy efficiency. When it comes to explaining why the EPC has such a low impact, some of the interviewees explain that it is because of the lack of engagement, the certifiers just care about handling the certificate and the clients just care about the certificate because they need it to complete a transaction. With this, it is not clear if the users actually pay attention to the EPC. It is different in cases with new buildings, where the information in the EPC is more relevant for the owners since they are more concerned about 
the grade on the label, since they still can improve their labelling during the design phases. With this the certifier and the architect or the owner are more involved with the EPC and its results.

\subsection{Investment on the RLMs}

The cost of the EPC is strongly related to its quality and included in the objectives proposed in its application. The software, calculation type, certified training, and the procedure of the RLMs will govern the costs that homeowners are willing to accept. In Norway, homeowners can produce the certificate themselves online at no cost. As a result, accuracy might decrease, but it might provide more awareness on energy efficiency. On the other hand, certificates produced by a trained certifier should be more accurate, but also costlier, if a field visit is performed. Otherwise, it would not differ much from the self-assessment, since the inputs will be defined by construction year of the building. Most of the decisions related to the EPCs fabrication, design and execution will impact directly to the RLMs.

According to the CA-EPBD [33], accurate recommendations would be too costly for the homeowners, but the commitment of increasing the renovation rate and giving quality information about renovations strategies to the users still remains one of the aims of the energy labelling system. With this in mind the RLMs can be a powerful tool to accomplish these goals, and although this may be true, it has been reported as neither tailor-made nor as part of a holistic plan [51]. Which leads to suggest that the RLMs have not been exploited. Nevertheless, the EPC up-front cost should be seen as an investment with a high return rate [49].

The interviewees stated that the energy labelling is not regulated by a fixed price system, which means that the price is defined by the market. The certifiers claim that the price of the EPC is set according to the hours that it would take to make a certificate, and that the quality of the recommendations will directly depend on the fees, such that EPCs that are more detailed normally will be more expensive. For example, to visit the building is not mandatory and hence, this can be skipped to make the procedure faster and cheaper, but therefore less accurate. With regards to the question about what they consider the most expensive task (time-consuming), the responses were diverse; for some of them, it is to collect the documentation, but in some countries, this can be done by the owner. Others claimed that modelling the building in the software would consume most of the time, whereas in another case it was highlighted that uploading the EPC inputs into the system was the most time-consuming activity since it means re-doing the same procedure as in the software but in the system. In many of the interviews, the certifier claimed that the EPC has become a business model for many companies, especially for new buildings where EPCs are performed in mass, lowering the quality of the EPC, and leaving behind single houses, since they are the less profitable cases for a large company. For independent certifiers, dwellings' EPCs might provide the main income, in which case the time spent per house becomes the most important factor for setting the cost of the certificate, since prices are influenced by the size and the location (how far from the certifier) of the dwelling. One of the interviewees explained that some companies ask for a minimum number of certificates, above that number the money collected for every new EPC would be a direct profit to the certifier. This encourages the increment of the process speed, which may contribute to reduce the quality of the EPC.

\subsection{Management and Data Collection}

To evaluate the impact of the EPC and other related policies in the renovation of the building stock, data from the EPC should be gathered and processed. However, many MSs have not yet presented an EPC database [47], mainly because it is not a mandatory requirement by the EPBD [33,49]. An EPC database refers to any centralized system, this may be an online platform or simply a spreadsheet, which periodically or systematically gathers information on the energy performance of all new and renovated buildings (as a minimum) [25]. The EPC database is one of the most effective ways to measure the impact of the EPC on the renovation goals [12,33,52]. Data can help to understand the housing stock, monitor energy efficiency progress and develop strategies at different levels [52,53], e.g., 
by defining building performance baseline, establishing energy policies and helping to design funding schemes for building refurbishment [54]. However, an official centralized European database has not been created [55] and only 24 MSs have presented an EPC database [33,49]. The details of the data collected varied, for instance, some states do not record the actual or potential savings or the suggested measures. Despite the fact that most EPCs contain details about the main characteristics of the certified buildings, this information is not monitored in the databases $[49,56]$. Furthermore, in some states with a functional database, the content is not available to policymakers [33,55]. Another important aspect that EPC should cover is to provide information to building owners to actually perform the suggested measures, through funding opportunities, and linking them with qualified professionals. This is especially important since owners are more likely to undertake renovation activities when supportive mechanisms are present [30]. However, mandatory training is only required in $14 \mathrm{MSs}$, in some states only when there is a lack of education and professional experience [49]. This may explain why studies have shown that users do not receive such information, and even more, that they do not trust the content that is provided [41].

The interviews confirm that some type of store system has been created for the EPCs. Nevertheless, whether a post data analysis is performed remains unknown. In addition, the certifiers were asked about their awareness of other instruments or programs that are available for contributing by any means to accomplish the renovations. Most of the interviewees have some knowledge about incentives and programs available; however, they were usually not up-to-date in those matters and most of the information that they handled was more about the general purpose of the programs rather than providing specific information about how to actually apply for it, or their requirements.

All the certifiers interviewed agreed that clients never ask for information about the recommendations or financial benefits to assist in the renovations. The most common concern is how much the EPC is going to cost and how long it will take. In addition, most interviewees detailed that the EPC is delivered by mail, so no further interaction with the client relating to the results is arranged. They also mentioned that they have not been instructed to provide any verbal information to the client, since observations and further recommendations are already written on the certificate. To the question about whether an energy audit would be adequate as an option to obtain cost-optimal measures, most of the interviewees agree that would be an ideal approach but impractical due to the cost that it implies. One certifier commented that something in between a field visit and an energy audit would be the most suitable to replace the current system.

\section{Discussion}

The results gathered in this study are in line with remarks by the evaluation of Directive 2010/31/EU, which states that a new direction must be taken to remove the barriers from the RLMs. Based on the extensive review of the current evidence and the information provided in in-depth interviews, the key aspects that have not been resolved, and suggestions on how to overcome these shortcomings, are discussed.

Accuracy and trust of the measures: The lack of definition and clear procedure to develop the RLMs has led to an open design of the development procedure. Instead of innovating and investing in accuracy, the RLMs seem to follow the minimum requirements by just handing out a list of general renovation suggestions. Efforts to improve these tools should seek as a goal to provide ready-to-use measures rather than inspirational measures.

One way to improve the accuracy is to decouple the RLMs from the standardized EPC procedure. With this, more accurate data can be obtained from updated calibration techniques [41] such as smart meters to enhance the input data [11], allowing predicted savings related to costs and energy that are more realistic. Suggestions about using the RLMs independently can be found in previous studies where it is recommended that the RLMs could form a basis for other policy instruments [57].

Relevance of the information delivered: To change the view of the EPC as a bureaucratic procedure, key stakeholders should be engaged. Capturing the attention of the owners is required to 
improve the results quality by introducing technical information that is relevant to the users, such as costs, savings, funding opportunities and how and when to carry out the measures. However, several benefits which could promote and increase the refurbishment activities are currently not incorporated in the RLMs system, such as the potential enhancement of the indoor environment. An indicator such as the increase of health and comfort levels is one of the concerns of the homeowners, according to the literature $[31,58,59]$. This represents a challenge since some comfort-related issues are not directly translatable in terms of energy and emissions savings in the cost-optimal analysis [60]. Research exploring the particular need for owner-occupiers to developed retrofit solutions, have identified multiple benefits [61].

Technical knowledge and skills: Many of the requirements for the RLMs are in doubt, since it is not clear whether these are correctly covered-such as cost-optimality, instructions to where to find detailed information, procedures on how to implement the measures, the link with incentives, or funding. Many of these requirements can be assigned to the certifier, and with this, a promoted effective approach can be used such as face-to-face tailored advice [62]. The certifier should have the role as consultant, detailing the results to the owners, highlighting improvements detected and guiding them through the renovation possibilities. To do so, technical knowledge should be delivered to the certifier, with these clear procedures and systematical check lists on how to carry out an inspection and how to deliver the information to the owners. Despite the increase in prices that the introduction of these techniques means, several improvements can be made to the current procedure to reduce the time consumed, and with it the cost. Such as investing in more friendly assessment software, exploring technologies to build systematically the 3D model, capturing the data from previous certificates, building a cost database linked with the software to estimate the investment, or automating the introduction of the results from the software to the labelling system.

Data collection, analysis, and use: Energy performance indicators are critical ingredients in a wide variety of policy measures. However, without the capacity to collect, analyze and use data pertaining to energy consumption in buildings, government officials and building professionals alike will not be able to use them. EPC design should be treated as a living process where progress should be measured, constantly seeking for improvement. Policy makers should be able to use the RLMs data to inform their decisions. Although in some countries the database has already been used by policymakers, greater benefits can be obtained by incorporating the results of the RLMs as indicators for the evaluation of complementary programs.

\section{Conclusions}

Despite the limitations in the number of countries covered, this study presents important findings in the understanding of the RLMs, reporting different orders of weaknesses, both at policy and at a technical level. These are valuable given the consensus on the importance of retrofitting the existing building stock and the need to improve the certification system as an information tool to accomplish this goal. They can useful for policymakers and labelling tools developers, especially after the directive amendment, which does not propose changes to the RLMs, even though in its current form it is not delivering the expected results. The main conclusion that can be drawn is that the RLMs do not present any evidence that by applying the recommended measures, benefits would be granted-such as recovery of the investment, indoor environment improvement, increase of the value of the property, or energy bill reduction. This conclusion follows from the fact that it is not required to demonstrate in the certificate that the recommendations have been validated, furthermore, key tasks that may sustain their use are not incorporated in the certification process, such as field visits, energy saving analyses, financial assessments, or even face-to-face meetings. If the certifier wants to test the recommendation, the certification tools are not designed for such a task. Poor results are obtained under the standard RLMs method, where measures from a pre-established list are selected by a certifier or homeowner, with no order of priority or instructions for their application. It is hard to trust that these measures are the most appropriate or even cost-effective. 
To overcome the shortcomings, several improvements need to be made to fulfill the ambitions of the RLMs. The results from the in-depth interviews show that the time spent and the provided tools have a strong role in the outcomes since they would define the cost of the EPC. By optimizing the time, field visits should be possible to accommodate without increasing the cost of the certificate overmuch. In line with time optimization, specialized tools should be developed to produce recommendations, such as energy performance calculation tools tailored to produce the RLMs, including automatized iteration, financial assessment, and concrete benefits as well as energy savings. These measures aim to obtain non-standardized results with credible benefits that effectively help homeowners in the decision-making on retrofitting.

\section{Limitations and Future Work}

The results presented do not cover all EU member states, so their interpretation is subject to limitations and they might not be representative of countries that have designed a more sophisticated RLMs system. However, to our knowledge, innovation beyond the EPBD requirements has not been done. The support of recent scientific material through reports and papers strengthens the analysis carried out, confirming that an effective proposal has not yet been found to concretize the approaches of the RLMs.

The collected material and its subsequent analysis are the basis for the development of a tool concept to propose customized RLMs. The tool will focus on covering the current procedure shortcomings and the needs of the certifiers, keeping the cost at a minimum, with the aim to deliver higher quality RLMs that are helpful for the buildings' owners.

Funding: This research received no external funding.

Conflicts of Interest: The authors declare no conflict of interest.

\section{References}

1. Visscher, H. The Progress of Energy Renovations of Housing in the Netherlands. In Proceedings of the World Sustainable Built Environment Conference (WSBE17): Transforming Our Built Environment through Innovation and Integration: Putting Ideas into Action, Hong Kong, China, 5-7 June 2017; Construction Industry Council: Hong Kong, China, 2017; pp. 1121-1125.

2. Baek, C.; Park, S. Policy measures to overcome barriers to energy renovation of existing buildings. Renew. Sustain. Energy Rev. 2012, 16, 3939-3947. [CrossRef]

3. Filippidou, F.; Nieboer, N.; Visscher, H. Are we moving fast enough? The energy renovation rate of the Dutch non-profit housing using the national energy labelling database. Energy Policy 2017, 109, 488-498. [CrossRef]

4. Pombo, O.; Rivela, B.; Neila, J. The challenge of sustainable building renovation: Assessment of current criteria and future outlook. J. Clean. Prod. 2016, 123, 88-100. [CrossRef]

5. Häkkinen, T. Systematic method for the sustainability analysis of refurbishment concepts of exterior walls. Constr. Build. Mater. 2012, 37, 783-790. [CrossRef]

6. Eurostat. Consumption of Energy. Available online: http://ec.europa.eu/eurostat/statistics-explained/ index.php/Consumption_of_energy (accessed on 4 June 2018).

7. Ürge-Vorsatz, D.; Danny Harvey, L.; Mirasgedis, S.; Levine, M.D. Mitigating $\mathrm{CO}_{2}$ emissions from energy use in the world's buildings. Build. Res. Inf. 2007, 35, 379-398. [CrossRef]

8. European Commission. Proposal for a Directive of the European Parliament and of the Council Amending Directive 2010/31/EU on the Energy Performance of Buildings; European Union; European Commissioin: Brussels, Belgium, 2016.

9. European Commission. Communication from the Commission to the European Parliament, the Council, the European Economic and Social Committee and the Committee of the Regions. In A Roadmap for Moving to a Competitive Low Carbon Economy in 2050; European Commission: Brussels, Belgium, 2011.

10. European Commission. Questions and Answers on 2030 Framework on Climate and Energy-MEMO/14/40; European Commission: Brussels, Belgium, 2014; p. 9. 
11. European Commission. Commission Staff Working Document: Evaluation of Directive 2010/31/EU on the Energy Performance of Buildings. Accompanying the Document Proposal for a Directive of the European Parliament and of the Council Amending Directive 2010/31/EU on the Energy Performance of Buildings; European Commission: Brussels, Belgium, 2016; p. 109.

12. Artola, I.; Rademaekers, K.; Williams, R.; Yearwood, J. Boosting Building Renovation: What Potential and Value for Europe? Study for the iTRE Committee, Commissioned by DG for Internal Policies Policy Department A; European Parliament: Brussels, Belgium, 2016; p. 72.

13. Neme, C.; Gottstein, M.; Hamilton, B. Residential Efficiency Retrofits: A Roadmap for the Future. Regulatory Assistance Project 2011. Available online: https://www.raponline.org/wp-content/uploads/2016/05/rapneme-residentialefficiencyretrofits-2011-05.pdf (accessed on 20 August 2018).

14. Banfi, S.; Farsi, M.; Filippini, M.; Jakob, M. Willingness to pay for energy-saving measures in residential buildings. Energy Econom. 2008, 30, 503-516. [CrossRef]

15. Häkkinen, T.; Belloni, K. Barriers and drivers for sustainable building. Build. Res. Inf. 2011, 39, $239-255$. [CrossRef]

16. Amstalden, R.W.; Kost, M.; Nathani, C.; Imboden, D.M. Economic potential of energy-efficient retrofitting in the Swiss residential building sector: The effects of policy instruments and energy price expectations. Energy Policy 2007, 35, 1819-1829. [CrossRef]

17. Achtnicht, M. Do environmental benefits matter? Evidence from a choice experiment among house owners in Germany. Ecol. Econ. 2011, 70, 2191-2200. [CrossRef]

18. Knight, R.L.; Lutzenhiser, L.; Lutzenhiser, S. Why Comprehensive Residential Energy Efficiency Retrofits are Undervalued. In Proceedings of the 2006 American Council for an Energy-Efficient Economy Summer Study Conference, New York, NY, USA, 13-18 August 2006.

19. Zaki, W.R.M.; Nawawi, A.H.; Ahmad, S.S. Economic assessment of Operational Energy reduction options in a house using Marginal Benefit and Marginal Cost: A case in Bangi, Malaysia. Energy Convers. Manag. 2010, 51, 538-545. [CrossRef]

20. Dowson, M.; Poole, A.; Harrison, D.; Susman, G. Domestic UK retrofit challenge: Barriers, incentives and current performance leading into the Green Deal. Energy Policy 2012, 50, 294-305. [CrossRef]

21. Murphy, L. The influence of the energy performance certificate: The Dutch case. Energy Policy 2014, 67, 664-672. [CrossRef]

22. Gohardani, N.; Af Klintberg, T.; Björk, F. Turning building renovation measures into energy saving opportunities. Struct. Surv. 2015, 33, 133-149. [CrossRef]

23. Schleich, J. Do energy audits help reduce barriers to energy efficiency? An empirical analysis for Germany. Int. J. Energy Technol. Policy 2004, 2, 226-239. [CrossRef]

24. Hoicka, C.E.; Parker, P.; Andrey, J. Residential energy efficiency retrofits: How program design affects participation and outcomes. Energy Policy 2014, 65, 594-607. [CrossRef]

25. Jamieson, M.; Brajterman, O.; Verstraeten, Y.; Arbon, J. Energy Performance of Buildings Directive (EPBD) Compliance Study; ICF International: Fairfax, VA, USA, 2015; p. 138.

26. Volt, J.; Fabbri, M.; Groote, M.D. Understanding Potential User Needs. A Survey Analysis of the Markets for Individual Building Renovation Roadmaps in Bulgaria, Poland and Portugal. 2018, p. 106. Available online: http:/ /ibroad-project.eu/wp-content/uploads/2018/04/iBRoad-Understanding-potential-userneeds.pdf (accessed on 18 September 2018).

27. Geissler, S.; Altmann, N. The Role of Recommendations in the Energy Performance Certificate. Concerted Action EPBD, 2015; p. 10. Available online: https:/ /www.epbd-ca.eu/wp-content/uploads/2011/05/CAEPBD-EPC-recommendations.pdf (accessed on 18 September 2018).

28. Jaffe, A.B.; Stavins, R.N. The energy-efficiency gap What does it mean? Energy Policy 1994, 22, 804-810. [CrossRef]

29. European Commission. Directive 2018/844/EU of the European Parliament and of the Council of 30 May 2018 on the energy performance of buildings (amending Directive 2010/31/EU). Off. J. Eur. Union 2018, 30, 2018.

30. Anagnostopoulos, F.; Arcipowska, A.; Mariottini, F. Energy Performance Certificates as tools to support and track renovation activities. Repéré sur le site du Build. Perform. Inst. Eur. 2015. Available online: http:/ / www.buildup.eu/en/practices/publications/energy-performance-certificates-tools-supportand-track-renovation-activities (accessed on 12 August 2018). 
31. Cappelletti, F.; Dalla Mora, T.; Peron, F.; Romagnoni, P.; Ruggeri, P. Building renovation: Which kind of guidelines could be proposed for policy makers and professional owners? Energy Proc. 2015, 78, 2366-2371. [CrossRef]

32. European Commission. Directive 2010/31/EU of the European Parliament and of the Council of 19 May 2010 on the energy performance of buildings (recast). Off. J. Eur. Union 2010, 18, 2010.

33. Concerted Action EPBD. Implementing the Energy Performance of Buildings Directive (EPBD)_Part A; ADENE: Lisbon, Portugal, 2016; p. 110.

34. Thomsen, K.E.; Wittchen, K.B. Implications of cost Optimum Calculations on Energy Performance Requirements in Member States; Aalborg University: Aalborg, UK, 2015.

35. Delmastro, C.; Mutani, G.; Corgnati, S.P. A supporting method for selecting cost-optimal energy retrofit policies for residential buildings at the urban scale. Energy Policy 2016, 99, 42-56. [CrossRef]

36. Mauro, G.M.; Hamdy, M.; Vanoli, G.P.; Bianco, N.; Hensen, J.L. A new methodology for investigating the cost-optimality of energy retrofitting a building category. Energy Build. 2015, 107, 456-478. [CrossRef]

37. Burman, E.; Mumovic, D.; Kimpian, J. Towards measurement and verification of energy performance under the framework of the European directive for energy performance of buildings. Energy 2014, 77, 153-163. [CrossRef]

38. Trust, C. Closing the Gap_Lessons Learned on Realising the Potential of Low Carbon Building Design; Carbon Trust London: London, UK, 2011.

39. Gram-Hanssen, K.; Bartiaux, F.; Jensen, O.M.; Cantaert, M. Do homeowners use energy labels? A comparison between Denmark and Belgium. Energy Policy 2007, 35, 2879-2888. [CrossRef]

40. Murphy, L. The influence of energy audits on the energy efficiency investments of private owner-occupied households in the Netherlands. Energy Policy 2014, 65, 398-407. [CrossRef]

41. Amecke, H. The Effectiveness of Energy Performance Certificates-Evidence from Germany; CPI Report; Climate Policy Initiative: Berlin, Germany, 2011.

42. DG Energy. Energy Performance Certificates in Buildings and Their Impact on Transaction Prices and Rents in Selected EU Countries; European Commission: Brussels, Belgium, 2013; p. 151.

43. Mahapatra, K.; Gustavsson, L. Energy renovation of single-family houses: Importance of economic aspects and suggested policymeasures. In Proceedings of the ECEEE 2013 Summer Study, BelambraLes Criques, France, 3-8 June 2013; European Council for an Energy Efficient Economy (ECEEE): Stockholm, Sweden, 2013; pp. 529-536.

44. Pettifor, H.; Wilson, C.; Chryssochoidis, G. The appeal of the green deal: Empirical evidence for the influence of energy efficiency policy on renovating homeowners. Energy Policy 2015, 79, 161-176. [CrossRef]

45. Moseley, P. Practical Approaches to the Building Renovation Challenge; European Commission EASME: Berlin, Germany, 2016; p. 13.

46. Backhaus, J.; Tigchelaar, C.; de Best-Waldhober, M. Key Findings \& Policy Recommendations to Improve Effectiveness of Energy Performance Certificates \& the Energy Performance of Buildings Directive. 2011, p. 47. Available online: https://www.ecn.nl/docs/library/report/2011/o11083.pdf (accessed on 18 September 2018).

47. Christensen, T.H.; Gram-Hanssen, K.; de Best-Waldhober, M.; Adjei, A. Energy retrofits of Danish homes: Is the Energy Performance Certificate useful? Build. Res. Inf. 2014, 42, 489-500. [CrossRef]

48. Bartiaux, F. A Qualitative Study on Home Energy-Related Renovation in Five European Countries: Homeowners' Practices and Opinions. 2011, p. 68. Available online: https://www.researchgate.net/ publication/269994052_A_qualitative_study_on_home_energy-related_renovation_in_five_European_ countries_homeowners $\backslash \mathrm{T} 1 \backslash$ textquoteright_practices_and_opinions (accessed on 18 September 2018).

49. Arcipowska, A.; Anagnostopoulos, F.; Mariottini, F.; Kunkel, S. Energy Performance Certificates across the EU. A Mapping of National Approaches; Buildings Performance Institute Europe (BPIE): Brussels, Belgium, 2014; p. 60.

50. Buildings Performance Institute Europe. 9 Ways to Make the Energy Performance of Buildings Directive (Epbd) More Effective; Buildings Performance Institute Europe (BPIE): Brussels, Belgium, 2016.

51. Boermans, T.; Dinges, K.; Grözinger, J.; Schäfer, M.; Förster, A.; Hermelink, I.; Manteuffel, B. Public Consultation on the Evaluation of Directive 2010/31/EU; Final Synthesis Report; European Commission: Brussels, Belgium, 2015; p. 108. 
52. Wittchen, K.B.; Van Diggelen, L. Database Management: Report from EPBD Concerted Action II Plenary Meeting, Berlin 15.-16. June, 2009; Working Paper; Research Portal: Hørsholm, Denmark, 2009; p. 32.

53. Costanzo, E.; Weatherall, D.; Androutsopoulos, A.; Onate, V.G. Can big data drive the market for residential energy efficiency? ECEEE Summer Study Proc. 2018, 1861-1869. Available online: https:/ / www.eceee.org/library/conference_proceedings/eceee_Summer_Studies/2017/8-monitoringand-evaluation-building-confidence-and-enhancing-practices/can-big-data-drive-the-market-forresidential-energy-efficiency/2017/8-295-17_Costanzo.pdf/ (accessed on 20 August 2018).

54. Altmann-Mavaddat, N.; Tinkhof, O.M.a.; Simader, G.; Arcipowska, A.; Weatherall, D. Report on Existing Monitoring Initiatives and Database Systems-From Databases to Retrofit Action: How European Countries Are Using Energy Performance Certificate (EPC) Database Systems. Eur. Portal Energy Effic. Build. 2015, 70. Available online: https://www.energyagency.at/fileadmin/dam/pdf/projekte/gebaeude/Report_on_ existing_monitoring_initiatives_and_databases.pdf (accessed on 20 August 2018).

55. Arcipowska, A. Making European Buildings Data Useful for Policy-Making Process. In World Sustainable Energy Days Next 2014; Springer: Berlin, Germany, 2015; pp. 11-18.

56. Atanasiu, B.; Constantinescu, T. A comparative analysis of the energy performance certificates schemes within the European Union: Implementing options and policy recommendations. Energy Effic. First Found. Low Carbon Soc. ECEEE 2011. Available online: https:/ / ec.europa.eu/energy/intelligent/projects/sites/ieeprojects / files / projects / documents /impact_cross_country_comparison_and_evaluation.pdf (accessed on 20 August 2018).

57. Joosen, S.; Zegers, F. Improving Energy Performance Assessment and Certification Schemes by Tests-Cross Country Evaluation of Energy Performance Certification. IMPACT/34/2006/WP3. November 2006, p. 56. Available online: https:/ /ec.europa.eu/energy/intelligent/projects/sites/iee-projects/files/projects / documents/impact_cross_country_comparison_and_evaluation.pdf (accessed on 18 September 2018).

58. Gram-Hanssen, K. Existing buildings-Users, renovations and energy policy. Renew. Energy 2014, 61, 136-140. [CrossRef]

59. Munro, M.; Leather, P. Nest-building or investing in the future? Owner-occupiers' home improvement behaviour. Policy Politics 2000, 28, 511-526. [CrossRef]

60. Becchio, C. Assessment of Energy and Cost Effectiveness in Retrofitting Existing Buildings. Ph.D. Thesis, Politecnico di Torino, Turin, Italy, 2013.

61. Haines, V.; Mitchell, V. A persona-based approach to domestic energy retrofit. Build. Res. Inf. 2014, 42, 462-476. [CrossRef]

62. Benders, R.M.; Kok, R.; Moll, H.C.; Wiersma, G.; Noorman, K.J. New approaches for household energy conservation-In search of personal household energy budgets and energy reduction options. Energy Policy 2006, 34, 3612-3622. [CrossRef]

(C) 2018 by the author. Licensee MDPI, Basel, Switzerland. This article is an open access article distributed under the terms and conditions of the Creative Commons Attribution (CC BY) license (http://creativecommons.org/licenses/by/4.0/). 